REVISTA ANDALUZA DE ANTROPOLOGÍA.

NÚMERO 13:

SEPTIEMBRE DE 2017

ISSN 2174-6796

[pp. 53-84]

http://dx.doi.org/10.12795/RAA.2017.13.03

Fecha de Recepción: 18/07/2017

Fecha de Aceptación: 09/07/2017

\title{
VALORES CULTURALES, DISCURSOS Y CONFLICTOS EN TORNO A LA CAZA. EL CASO DE LAS MONTERÍAS SOCIALES EN ANDALUCÍA
}

\section{CULTURAL VALUES, DISCOURSES AND CONFLICTS OVER HUNTING. THE CASE OF THE "SOCIAL" MODALITY OF BIG GAME HUNTING IN ANDALUSIA.}

\section{David Florido del Corral}

Grupo de Investigación GEISA. Universidad de Sevilla

\section{Pablo Palenzuela}

Grupo de Investigación GEISA. Universidad de Sevilla

\section{Resumen}

La extensión de la montería, en la diversidad de sus formas de gestión, se ha desarrollado notablemente en los últimos cuarenta años, reflejando el arraigo social de la misma en los territorios serranos de Andalucía, fenómeno que no es atribuible solo a la funcionalidad económica de la actividad, sino principalmente a los valores socioculturales, elementos patrimoniales e históricos (aunque de una historicidad reciente) que son explicados en la primera parte del artículo. Entre estos valores, destacamos el modelo cognitivo mediante el que los cazadores de las monterías denominadas "sociales" experimentan y sienten su relación dentro del socioecosistema del que forman parte. En la segunda parte, exponemos el conflicto entre los modelos de naturaleza (tratados como 'ontologías') que defienden las organizaciones de la caza y las organizaciones ecologistas, sugiriendo 
finalmente la necesidad de un modelo de gobernanza que tenga en cuenta la diversidad de esas percepciones y un diálogo entre ellas.

\title{
Palabras clave
}

Montería (Caza Mayor), Conflicto Ambiental, Patrimonio Cultural, Ontología Política, Andalucía.

\begin{abstract}
The hunting for big game has been developed notably in the recent decades in Andalusia (Spain), according to a diversity of management regimes. This social extension reflects the social entrenchment of this activity, what it is explained before by socio-cultural, historic and heritage values than by its economic importance, such as it is described during the first part of this paper. Among these values, we have wanted to stress the cognitive pattern that mediates the relations between hunters who exert the so-called "social" hunting for big game, addressing the sensorial and ethical aspects of this web of relations enacted by them. In the second part, the conflict on the "regimes of Nature" (considered as 'ontologies') claimed by environmentalist and hunting organizations is focused. Finally, we suggest the suitability of promoting a governance debate on hunting taking into account the diversity of perceptions of nature-society relationships.
\end{abstract}

\section{Key Words}

Big Game Hunting, Environmental Conflict, Cultural Heritage, Political Ontology, Andalusia.

\begin{abstract}
"En las cacerías también respetamos ciertas leyes caballerescas y prácticas, respetamos a los animales salvajes, hasta donde los exijan las costumbres del lugar, pero la caza sigue siendo un sacrificio, o sea, el vestigio deformado y ritual de un acto religioso ancestral, de un acto primigenio de la era del nacimiento de los humanos. Porque no es verdad que el cazador mate para obtener su presa. Nunca se ha matado solamente por eso, ni siquiera en los tiempos del hombre primitivo... A la caza le acompañaba siempre un ritual tribal y religioso".
\end{abstract}

Sándor Márai (2013) [1942] El último encuentro. Ediciones Salamandra, p. 114-115.

\section{INTRODUCCIÓN}

A partir de un acercamiento etnográfico sobre la montería como modalidad específica de caza mayor, y con especial énfasis en las denominadas monterías "sociales", pretendemos poner de relieve los valores culturales de la actividad cinegética, teniendo en cuenta expresiones simbólicas y rituales, formas de sociabilidad, formas de gestión, y saberes que 
contiene esta práctica, caracterizada por una doble orientación estratégica, recreativa o/y comercial, y que socialmente goza de una notable extensión en el medio rural andaluz.

Desde un abordaje holístico, forzosamente sintético, focalizamos nuestro análisis en las monterías denominadas "sociales", en particular, en las relaciones ecosistémicas entretejidas en el territorio forestal en el que la caza tiene lugar, abordando la doble naturaleza de esas relaciones: a) una vertiente pragmática que guía las estrategias y las prácticas en el monte de los individuos que poseen un saber hacer empíricamente aprendido y b) la dimensión sensorial, emocional y ética que sustenta la orientación cognitiva de los actores sociales sobre la actividad en sí misma y sobre el espacio antropizado en el que se ejercita. Partimos de la hipótesis de que la imbricación de ambas dimensiones genera un conjunto de prácticas y valores culturales que justifican su reconocimiento como patrimonio cultural inmaterial. En un segundo momento, tratamos de la caza como objeto de disputa y conflicto en la arena social y política, entre dos formas de concebir la naturaleza, y de actuar dentro de ella, la propia del movimiento ecologista y la de asociaciones representativas del sector cinegético. En un conflicto que queremos abordar desde el enfoque de la ontología política, ponemos de manifiesto que en ese debate no se tiene en cuenta el modelo humano-ambiental que encarnan los que ejercen la actividad en la modalidad más extendida socialmente, la de las sociedades de cazadores.

El artículo se apoya en la información obtenida en el trabajo de campo realizado para la elaboración de la propuesta de declaración de la montería y la rehala como actividad etnológica y su inscripción como Bien de Interés Cultural de Andalucía.

\section{LOS VALORES PATRIMONIALES DE LA MONTERÍA Y LA REHALA ${ }^{1}$}

La montería y la rehala son los dos componentes indisociables de una modalidad cinegética original y de enorme profundidad temporal, con un ámbito territorial que incluye a una buena parte del territorio andaluz y que se practica cada temporada cinegética desde octubre a febrero, preferentemente en los ecosistemas de bosque mediterráneo de Andalucía.

La primera característica a resaltar, aunque no sea exclusiva de la caza mayor, es que se trata de una actividad colectiva en la que cooperan el grupo de cazadores (monteros) y el de rehaleros con sus perros, cada uno con funciones complementarias. La montería se desarrolla a lo largo de una jornada en un cazadero (la "mancha", en el argot montero)

1. Los epígrafes primero y segundo recuperan parte del contenido del Informe Técnico para la "Declaración de la Montería y la Rehala como BIC de Andalucía" presentado por la Federación Andaluza de Caza en la Consejería de Cultura, dirigido por el Dr. Pablo Palenzuela (ref. 2921/0819), realizado entre noviembre de 2016 y febrero de 2017. 
previamente delimitado y con sus puestos de tiro situados en su perímetro ("las armadas de cierre") o en su interior ("armadas de traviesa"), en los que se colocarán los monteros con sus armas. Los rehaleros recorren el cazadero con sus perros, siguiendo un recorrido planificado, para acosar a las piezas encamadas (jabalíes, venados, muflones y gamos, principalmente) y obligarlas a seguir sus "querencias", zonas de paso próximas a las armadas. Cada armada comprende un número variable de puestos o "puertas" (entre cuatro y diez, normalmente) y está a cargo de un "postor" que acompañará hasta su puesto a los monteros de su armada y les indicará la dirección que seguirán las rehalas, las probables vías de escape de las reses y los lugares para efectuar el disparo con alta probabilidad de acierto y mayor seguridad.

Las monterías actuales reproducen, en lo esencial, un mismo desarrollo pautado en las siguientes fases, con un alto grado de ritualización: a) junta de monteros y rehaleros a primeras horas de la mañana; b) desayuno colectivo y sorteo de los puestos; c) ubicación en las armadas y suelta de las rehalas; d) batida de la mancha por los rehaleros y ejecución de lances por los monteros; e) "junta de carne", con la exposición de las reses abatidas; y f) almuerzo colectivo y vuelta a casa, de forma inmediata por parte de los monteros y más tarde por parte de los rehaleros.

Durante los once siglos en que se tienen evidencias documentales de la montería, esta variedad cinegética ha experimentado, como no podía ser de otra forma, un proceso de continuidad y cambio, en consonancia con las vicisitudes históricas. Originariamente, se instituyó y se codificó como una actividad exclusiva de la realeza y de la aristocracia feudal y eclesiástica -su práctica por el resto de los estamentos fue prohibida y fuertemente penalizada-. Un hito importante en su evolución histórica fue el uso, desde el siglo XVI, de armas de fuego (arcabuces y escopetas), con las que se abre la fase de modernización técnica, y de relativa democratización de las monterías, que se concreta en con la Real Orden de 1837 que extendió el derecho de caza a toda la población. Desde entonces, es la accesibilidad a los cotos el principal factor de generalización de la actividad.

En la segunda mitad del siglo XX, con la aprobación de la Ley de Caza de 1970, que establece el derecho exclusivo a los aprovechamientos cinegéticos en los cotos, se autoriza el cerramiento con vallas cinegéticas y se regula la creación de las Sociedades Deportivas de Caza, produciéndose un incremento exponencial de las monterías y su diversificación. Esta regulación de la montería ha significado la transición definitiva entre dos "culturas cinegéticas", según la distinción que hace Bertrand Hell: desde la "caza de recolección" asociada a la idea del derecho libre y general a la caza de los animales que "crecen solos" a la "caza de cosecha" en la que "el cazador se percibe como el administrador de la población animal, vigilia y mantiene una población óptima de reses en su territorio de caza" (Hell, 2001:239). Ello supone la aplicación de una gestión cinegética que lo legitima como usufructuario de ese bien. 
Como resultado de la evolución en las últimas décadas, podemos establecer la siguiente tipología de monterías: a) monterías sociales o de Sociedades Deportivas de Caza; b) monterías de Peñas de Monteros; c) monterías de Invitación; y d) monterías comerciales u 'orgánicas'. Las cuatro modalidades mantienen una similar secuencia de fases en su ejecución formal, pero hay una racionalidad subyacente que condiciona la producción de valores culturales, de significados y de la apropiación del medio: mientras que a las dos primeras les corresponde un modo de gestión que persigue el mantenimiento del coto y una población mínima de reses que garantice el acceso de los socios a los cotos, a las monterías "comerciales" les corresponde un modelo en la que existe la búsqueda explícita de rentabilidad económica entre sus promotores, tanto al gestionar la dehesa y el bosque como las poblaciones de animales. Un tanto peculiares desde el punto de vista de su racionalidad económica son las monterías de invitación, que a los efectos de este artículo no vamos a tratar ${ }^{2}$. Independientemente de que en cualquiera de las modalidades puedan apreciarse prácticas culturales con un valor patrimonial, nos detendremos específicamente en la descripción de los valores patrimoniales del modelo de monterías "sociales" (tipo a), para retomar la diversidad de prácticas monteras al plantear el conflicto en torno a las relaciones humano-ambientales que se despliegan en las distintas monterías.

Es preciso un breve apunte para diferenciar los conceptos de cultura y patrimonio, por mucho que ambos estén claramente relacionados (Carrera, 2016). La cultura refiere a la trama simbólica (de significados), de reglas y principios de organización cognitiva, cambiantes, que se expresan en un conjunto articulado de procesos materiales, sociales e ideáticos, de formas de vida (Díaz de Rada, 2010). Mientras que el patrimonio cultural es proceso social de selección de algunos elementos significativos que constituyen la experiencia cultural, para dotarlos de un valor icónico, representativo, por parte de distintas agencias sociales (Ariño, 2002). No es infrecuente, como el caso que estudiamos aquí demuestra, que ese proceso de selección sea socialmente contestado, genere distintas lecturas y se desarrolle en el contexto de un conflicto. Por lo tanto, preferimos hacer referencia a "procesos de patrimonialización", pues de este modo eludimos el supuesto carácter objetivo, no discutible, de los elementos que entran en juego en los procesos sociales de definición y selección de valores patrimoniales. En cualquier caso, en la relación de elementos que se mencionan a continuación, tenemos especialmente en cuenta el concepto de Patrimonio Inmaterial definido por la UNESCO en su

2. Las monterías "de invitación" son organizadas por grandes propietarios en sus fincas y discurren dentro de una lógica de reciprocidad equilibrada, al acudir personas de posiciones y estatus social similar, algunos de los cuales amplían ese circuito de monterías de invitación reproduciendo en sus fincas una montería similar como contradón. En las monterías organizadas empresarialmente por "orgánicas", los promotores venden los puestos con la intención de recuperar la inversión que supone su organización. 
Convención de París de $2002^{3}$-que ha sido trasladado a la legislación estatal mediante la Ley 10/2015 de 26 de mayo para la Salvaguardia del Patrimonio Cultural Inmaterial-. Este concepto hace referencia a prácticas y representaciones (ideáticas), además de los conocimientos, técnicas, artefactos y lugares necesarios para que las "comunidades sociales" reconozcan un patrimonio cultural inmaterial propio. Lo que se destaca en esta definición es la relación de continuidad histórica de un colectivo respecto de esas prácticas y representaciones, que permite un sentimiento de identidad que se expresa en el tiempo y sobre un territorio, constituyéndolo. Entre los tipos de elementos que pueden ser considerados bajo esta categoría y que son aplicables a las monterías, destacamos: “c) los usos sociales, rituales, actos festivos; y d) conocimientos y usos relacionados con la naturaleza" (art. 2.1 del citado documento). A nivel autonómico, la Ley 14/2007 de Patrimonio Histórico de Andalucía incorpora igualmente la noción de bien cultural con valor inmaterial de la Convención de París, reconociendo que los bienes culturales con un valor etnológico (art. 2) pueden quedar inscritos en el Catálogo General del Patrimonio Histórico Andaluz (CGPHA) (art. 6) en la categoría de Actividad de Interés Etnológico4.

Queremos subrayar, de cualquier forma, el carácter socialmente reflexivo y políticamente conflictivo (Kockel, 2007) de los procesos de patrimonialización. Esto es, son resultado de estrategias sociopolíticas de colectivos sociales y, en este caso, han sido asociaciones del mundo de la caza (tanto de monteros como de rehaleros) las que han solicitado la declaración de las monterías y rehalas como Bien de Interés Cultural y su inscripción en el en el CGPHA. El documento redactado para proponer la declaración patrimonial de las monterías y rehalas (ver nota 1) ha sido sometido a un proceso, también político, de confirmación, en el que han participado tanto sociedades de cazadores como ayuntamientos de zonas monteras andaluzas. Con ello se cumple con uno de los requisitos que UNESCO considera importantes para las declaraciones patrimoniales: que sean resultado de iniciativas sociales y no emanen exclusivamente, por tanto, ni de instancias políticas ni de expertos. Con la inevitable matización que exige la diferente

3. Convención Internacional para la salvaguardia del Patrimonio Cultural Inmaterial, celebrada en París. En concreto: "Prácticas y representaciones, juntamente con los conocimientos, técnicas, instrumentos, objetos, artefactos y lugares necesarios, que las comunidades y los individuos reconozcan como patrimonio cultural inmaterial propio, y que sean compatibles con los principios universalmente aceptados de derechos humanos, equidad, sostenibilidad, y respeto mutuo entre las comunidades culturales. Este patrimonio cultural inmaterial es constantemente recreado por las comunidades en respuesta a su entorno y a sus condiciones históricas de existencia, y les inspira un sentimiento de continuidad e identidad, promoviendo así la diversidad cultural y la creatividad humana [de la humanidad]" (Artículo 2.1. del documento citado). En el punto siguiente (2.2.) se señalan los aspectos concretos que deben ser considerados bajo el concepto: a) [formas de] expresión oral; b) artes de interpretación; c) usos sociales, rituales, actos festivos; y d) conocimientos y usos relacionados con la naturaleza.

4. Como se explica en el Informe citado en la nota 1, distintos artículos del Reglamento de aplicación de la Ley 14/2007 de Patrimonio Histórico de Andalucía sirven de contexto normativo para los valores que han sido seleccionados por su sentido patrimonial y que sintetizamos en este artículo. 
racionalidad subyacente a la variedad de monterías indicada, hemos podido constatar durante el trabajo de campo el siguiente catálogo de valores culturales:

\subsection{Sociabilidad, socialización y transmisión de saberes.}

La confluencia en un lugar y un tiempo determinados de un grupo de individuos dispuestos a compartir una práctica en un entorno "natural" genera un campo específico de sociabilidad distinto a los ámbitos y modos cotidianos de sus otras relaciones sociales. En el caso de las sociedades de cazadores, además, se da la circunstancia de que la actividad de sociabilidad, en relación a la caza, recrea y reproduce prácticas sociales informales que ya se producen en el campo, mediante un sinfín de actividades agroganaderas y forestales. Estamos ante un caso de articulación de relaciones sociales, por encima de relaciones de parentesco y afines, en relación con una actividad lúdica para sus miembros, que permite el intercambio de experiencias, la reiteración de relaciones, compartir un lenguaje, etc. (Escalera, 2012), y que adquieren un significado social diferente, al promoverse en un marco altamente ritualizado.

La tipología de las distintas modalidades de montería determina fórmulas de interacción social diferente entre los participantes, entre la cuadrilla de monteros y el anonimato de las monterías orgánicas (Sánchez Garrido, 2010). En el caso de las rehalas, igualmente, la diferente estructura entre las "tradicionales" (rehalero titular/propietario y perrero a su servicio) y las "deportivas/comerciales" (perrero a la vez que propietario) modula relaciones diferentes entre los perreros titulares de su rehala y aquellos que manejan en el monte la rehala de los propietarios.

Por la regularidad de la composición del colectivo de monteros (miembros de la sociedad deportiva de caza) y la continuidad de la actividad en un mismo terreno cinegético (el coto social), así como por la frecuencia de participación de los rehaleros locales o comarcales, las monterías organizadas sin ánimo de lucro por las sociedades deportivas de caza constituyen el modelo de actividad más proclive a una sociabilidad densa, reforzada a menudo por relaciones de parentesco, de amistad o de vecindad. Como se afirma en Sánchez Garrido (2009a) hay un 'tiempo cinegético', especialmente intenso en sus interacciones sociales, formas de aprendizaje y transmisión. En este tipo de monterías, la idea de pertenencia a una comunidad de cazadores diluye, sin eliminarlas, las diferencias internas de clase social, género, grupos de edad, de profesión, de formación, etc., al menos en el tiempo y espacio cinegéticos.

Las relaciones directas y personalizadas, cargadas de afectividad, son la pauta común en estos contextos, que tienen un marcado carácter local, así como la horizontalidad en las relaciones, independientemente de la posición y estatus socio-económico de los interactuantes. Las conversaciones entre los monteros giran de forma preeminente sobre sus experiencias cinegéticas, siguiendo una estructura narrativa regular, con unas pautas 
aceptadas tácitamente por el grupo. El montero transmite a los demás los detalles de su acción a partir de su interiorización selectiva de los hechos que le interesa resaltar o, en su caso, ocultar. "A la vez que trasmite su experiencia escucha la de los demás, creándose un diálogo, una comunicación que va configurando la identidad y el saber cinegético. Se vuelve a cazar, aunque no se esté en el campo" (Sánchez Garrido, 2010:37). Son los momentos previos y finales de la montería, en la junta de monteros y sorteo, y en el almuerzo y junta de carne, cuando esta sociabilidad se desarrolla plenamente, a través del comensalismo (almuerzo con migas y guisos de caza como recetas más extendidas) (figura 1). Igualmente, los perreros se reúnen en torno a viandas y bebidas que ellos mismos ponen a disposición de sus compañeros, mientras logran reunir a sus rehalas tras la cacería. En las cacerías sociales de la Baja Andalucía, a menudo acaban compartiendo su espacio y sus fandangos y sevillanas con el resto de grupos que han acudido a cerrar la montería (figura 2).

Figura 1 y Figura 2. Comensalismo y corro de fandangos en el almuerzo de campo tras montería en Paterna del Campo (Huelva)
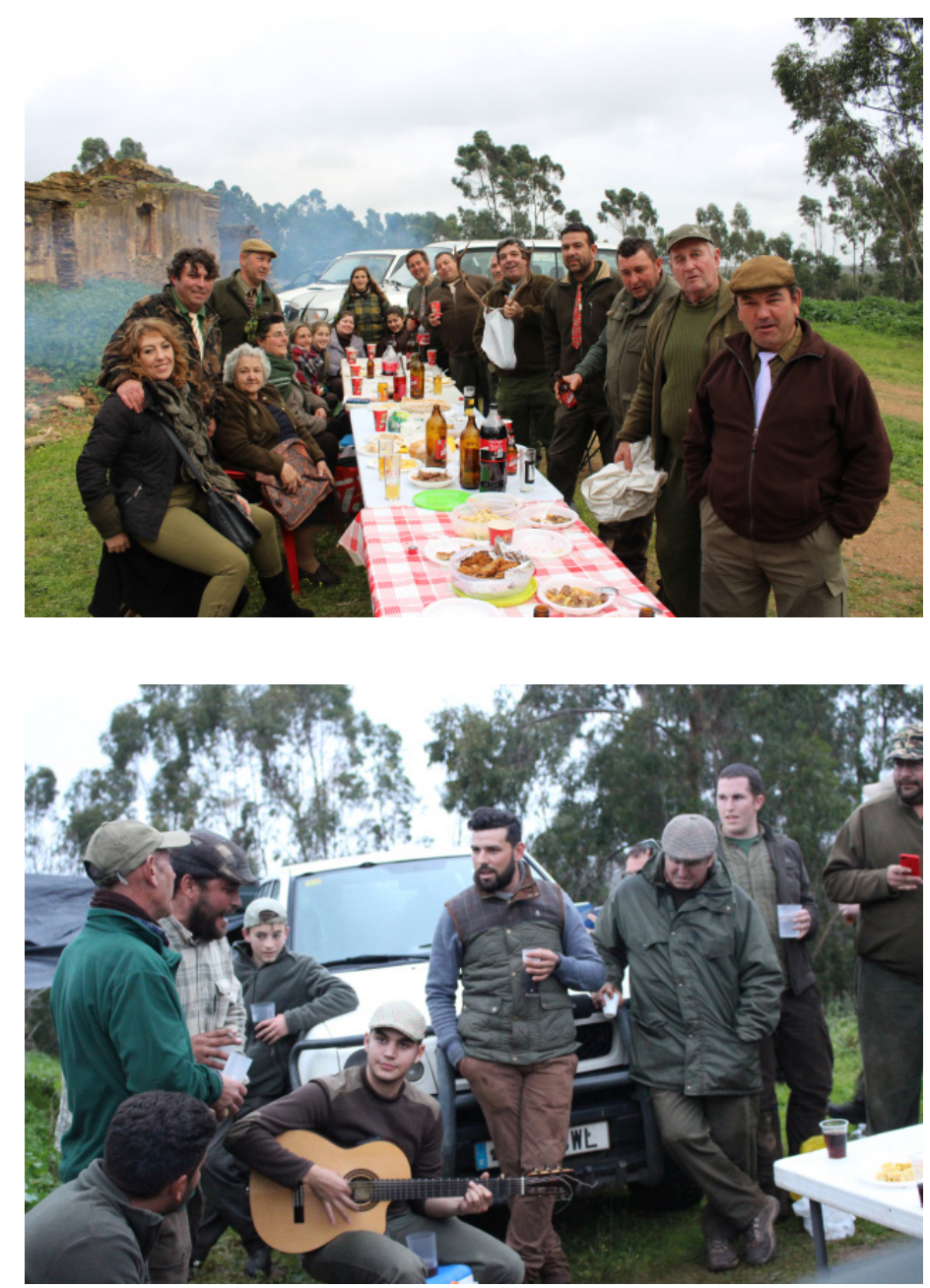

Autor: David Florido 
Entendemos por socialización el proceso de internalización, a nivel subjetivo, de normas, conductas, prácticas y valores que cada grupo humano define como marco regulador de la acción social. En el caso de la montería y la rehala, siguiendo la clásica distinción de Berger y Luckman, se trataría de una forma de socialización secundaria: "que induce al individuo ya socializado a nuevos sectores del mundo objetivo de su sociedad" (2003:163). A través de ese proceso, el sujeto va adquiriendo prácticas, habilidades, un saber hacer, pero también valores, códigos de conducta, símbolos y se va haciendo de un léxico particular.

Esta socialización, de la misma manera que la sociabilidad, está marcada por una segmentación de género, tanto entre los monteros como entre los rehaleros, que ha venido a reforzar la asignación normativa de sexo/género de los entornos sociales de la Andalucía serrana. El varón es en la mayoría de los casos el receptor de ese conocimiento cinegético, lo que supone que la montería y la rehala se convierten en una actividad mayoritariamente realizada por hombres dentro de un ambiente de fuerte virilidad. Ello no obstante, la progresiva incorporación de la mujer a la montería es un hecho evidente, aunque todavía escaso. Su presencia es cada vez menos objeto de incomprensión o rechazo; antes bien, suele ser motivo de admiración por lo que supone el hecho de romper barreras ideológicas que han limitado el desempeño por las mujeres de estas actividades.

En las trayectorias de nuestros informantes monteros y rehaleros se constata que el inicio habitual de ese proceso coincide con el periodo de su infancia o adolescencia y, muy frecuentemente, en su ámbito familiar (figura 3). Desde el momento que el/la niño/a o adolescente manifiesta su deseo de acercarse al mundo de la caza, y demuestra "tener afición”, es acogido por su mentor, normalmente el padre, el abuelo o un familiar, que le introducirá en el grupo y en ese nuevo universo, guiándolo en su proceso de aprendizaje hasta su integración en el colectivo a través de la socialización en los ambientes monteros.

Figura 3. Sorteo de puestos en la montería de la Sociedad de Cazadores de Paterna del Campo (Huelva)

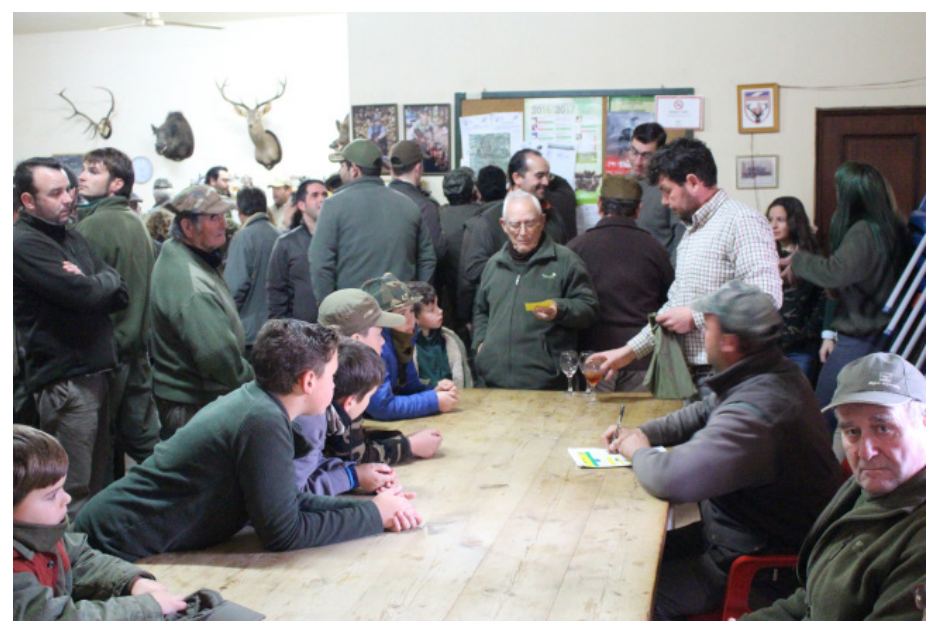

Autor: David Florido 
Este proceso de socialización se construye a través de su componente tanto material y técnico (técnicas y saberes del "oficio" de montero y rehalero), como ideático (valores, conductas, normas). En el primer caso, se trata de un conocimiento empírico basado en la práctica regular que proporciona la asistencia a las monterías acompañando a su mentor. El espacio para este aprendizaje es el monte: los futuros monteros desde el puesto de tiro y los aprendices de rehaleros "rompiendo la mancha". De este modo adquirirán la experiencia necesaria para, entre otras habilidades, manejar las armas con seguridad o guiar los perros en la mancha, "leer el campo" interpretando las huellas y rastros que dejan los animales, desarrollar su sentido de orientación, distinguir las especies arbóreas y arbustivas, etc. En definitiva, adquirir mediante la experiencia personal, el saber hacer del "oficio" de montero o rehalero, una verdadera cultura del trabajo en su doble componente material e ideacional (Palenzuela, 1995). Igualmente, los perreros hacen aprender a los canes "nuevos", seleccionándolos para que aprendan de los más experimentados.

\subsection{Asociacionismo}

La frecuencia y regularidad de esos modelos de sociabilidad han dado en la constitución de asociaciones formales. Desde los años setenta, al amparo del nuevo marco legal, se ha ido constituyendo una amplia red de Sociedades Deportivas de Caza de ámbito local que en Andalucía supera actualmente los dos millares -el segundo segmento de asociaciones, tras el de fútbol, por número de entidades, en Andalucía ${ }^{5}$. Una buena parte de ellas tienen como actividad central, si no exclusiva, la caza mayor y su objeto principal es proporcionar a sus socios la práctica cinegética en los cotos sociales, territorios cuyo aprovechamiento cinegético es exclusivo para los miembros de la sociedad. En algunas localidades, las actividades de montería se convierten en uno de los momentos para el regreso de migrantes que practican la actividad. Por lo demás, es la práctica regular y continuada en el tiempo de la montería lo la que favorece la relación que estas sociedades tienen con los cotos, entendidos como "lugares", tal como se explicará en el siguiente apartado.

Por su parte, las rehalas también han configurado una plataforma organizativa con la Asociación Española de Rehalas (AER), fundada en 1996 con el objeto de defender la rehala y de dignificar la figura del rehalero y el respeto a su labor en el monte, valorando adecuadamente la importancia de su trabajo. La importancia de este asociacionismo formal radica en que representan el marco adecuado en el cual se organizan las actividades cinegéticas, se garantizan los derechos de acceso a los cotos, se desarrolla el modelo de sociabilidad densa apuntado -tanto en relación a la caza, como en otros momentos del año- y se favorece la transmisión de prácticas y saberes.

5. Es significativo que el número de dichas sociedades de caza sea superior al de la totalidad de los municipios andaluces y en algunas localidades de gran tradición montera sus socios representan la tercera parte de la población adulta masculina 


\subsection{Ritualización}

La antropóloga francesa Odile Vincent (1987) afirmó el carácter ritual de las monterías, dada la delimitación de su tiempo, su celebración en un espacio distinto al cotidiano, el formalismo de la secuencia de acciones o la repetición de actos. Jiménez de Madariaga (2005) apunta en la misma línea, distinguiendo tres tipos de rituales en la caza: propiciatorios (como la invocación a la divinidad mediante el rezo que tiene lugar en la junta de monteros o la suerte que se ritualiza mediante el sorteo de los puestos), expiatorios y de iniciación. El rito de la "noviez" (hacerse novio) es el ritual más representativo y original de la montería y puede integrarse, al mismo tiempo, entre los expiatorios y los de iniciación (figura 4). Es un rito de paso, de “ordenación”, que se celebra cuando se abate la primera res en una montería, ritualizando el tránsito desde la condición de simple cazador al estatus de montero. Mediante una dramaturgia específica se reproduce un juicio penal: el cazador cumple el rol de "acusado", la res abatida es la prueba del "delito", mientras que el "tribunal" lo componen monteros veteranos, que explican un "pliego de cargos" por el "asesinato" de un animal, conducente a una "sentencia" (siempre inculpatoria) y un "castigo", que es ejecutado habitualmente por el grupo de rehaleros. La sanción decretada conlleva superar una serie de pruebas que pretenden demostrar la hombría del aprendiz de montero: impregnación con la sangre del animal, colocación de las vísceras en la cabeza del reo, corte de algunos mechones del cabello, embadurnamiento con huevos y harina, etc.), además del pago de una sanción que se concreta en la invitación a los asistentes y la propina a los podenqueros. Este ritual de iniciación puede reproducirse en cualquier modalidad de montería, pero su frecuencia es más alta en las monterías de sociedades deportivas de caza dado el mayor control del grupo sobre los monteros neófitos.

\section{Figura 4. Un montero joven sometiéndose al rito de la noviez}

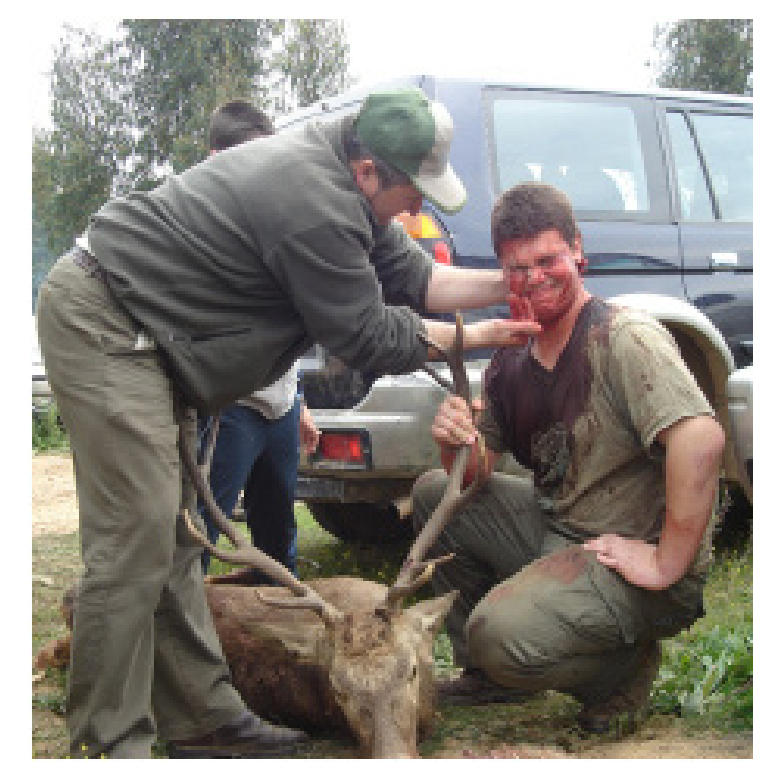

Autor: Francisco Hidalgo. 
En este mismo sentido, en las monterías sociales, es norma que los cazadores asuman una primera vez para la tarea de eviscerar al animal, "sacar el buche" (con la supervisión veterinaria) (figura 5). El neófito ha de abrir al animal con la ayuda de su navaja, aspirar sus humores, sentir en sus manos el calor de los órganos y fluidos que hacía poco estaban vivos..., fundirse con sus entrañas, en una experiencia de la continuidad de la vida y de la muerte que, para un no iniciado, podría ser traumática. Los cazadores más experimentados, entre bromas para poner en evidencia la inexperiencia del novato, van guiando el proceso para garantizar que se realiza adecuadamente desde el punto de vista técnico.

\section{Figura 5. Un montero saca el buche al ciervo abatido (Paterna del Campo, Huelva)}

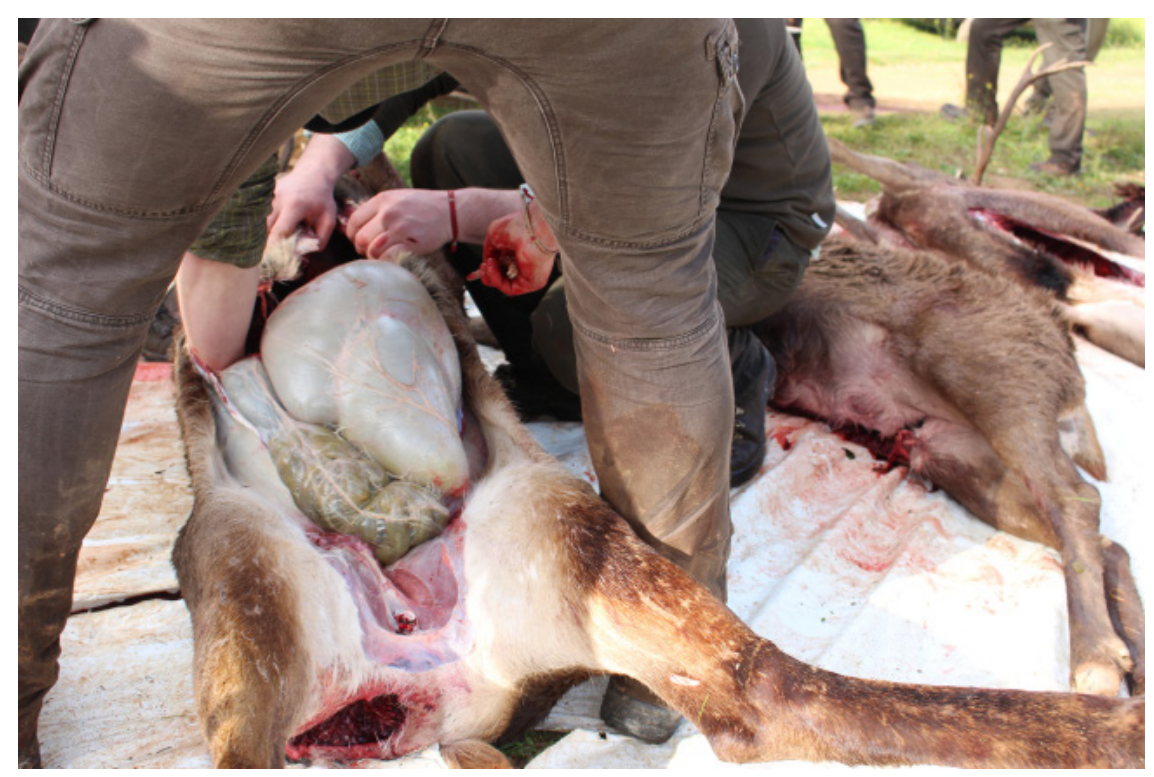

Autor: David Florido.

\subsection{Apropiación cognitiva del territorio.}

La investigación etnográfica desvela que otro de los valores culturales de la práctica de la montería y la rehala es la percepción del territorio, real material y real simbólica. La percepción del territorio y su significación real/material y real/simbólica no sigue un recorrido homologable ya que "el significado que adopta el territorio para cada sociedad viene marcado por la evolución de los usos y aprovechamientos del espacio y por las formas de apropiación de éste a lo largo de su proceso histórico" (Palenzuela y Hernández, 1995: 123).

Elespaciocinegético, el territorio decaza, puedefuncionarcomo marcadordeidentificación de un "nosotros" que lo usa para su disfrute, lo conserva y lo modifica al mismo tiempo que lo conoce en todas sus dimensiones, cuando la montería se ejercita regularmente por un colectivo estable de cazadores y rehaleros sobre un mismo territorio, como ocurre en las monterías organizadas por las Sociedades Deportivas de Caza. En este caso tiene lugar 
un proceso de apropiación cognitiva de ese espacio que se considera propio, más allá de las formas jurídicas que definen la propiedad. Aquí entendemos la "apropiación” como una noción más amplia que la de propiedad, al desbordar el marco jurídico e integrar una percepción de patrimonio, de legado colectivo y de usufructo real-simbólico (Palenzuela, 2005). Por el contrario, en las monterías organizadas empresarialmente, la propiedad supone una relación patrimonial, jurídicamente protegida y excluyente, que no implica la misma relación del montero respecto al territorio, en el que caza de forma esporádica, aún si lo hace con cierta continuidad. En todo caso, para él, el coto o la mancha es un espacio coyuntural, un mero punto geográfico, un lugar de tránsito, un "no-lugar", como lo califica Marc Augé (2001), un “paisaje de consumo” donde paga por cazar.

La apropiación cognitiva del espacio cinegético como referente simbólico por los monteros y rehaleros se manifiesta rotundamente en la modalidad de monterías sociales, encarnadas por las sociedades deportivas de caza, para quienes el coto es un patrimonio común, un legado de generaciones anteriores cuya conservación, orientada a la caza, es responsabilidad del colectivo. El coto no es "lugar de consumo", sino "un lugar de uso", de experiencia y constitución de su socialidad, con un carácter netamente político (nos pertenece, aunque no haya respaldo jurídico), desarrollada mediante un vínculo emocional del que es inseparable la apropiación cognitiva: se conoce su morfología, su historia, su toponimia, sus cualidades físicas, las relaciones ecológicas que lo caracterizan, etc., siendo la caza la que vehicula este proceso de patrimonialización -en el sentido de apropiación- a través de la socialización y transmisión generacional. Se trata, ante todo, de un paisaje humanizado, un paisaje cultural (Álvarez Munárriz, 2007).

\subsection{Relaciones humano-ambientales: el modelo cognitivo en las monterías sociales}

La racionalidad predominante en las monterías sociales no está orientada actualmente por una lógica alimentaria, aunque la carne de los animales sea vendida -en un mercado crecientemente internacionalizado- y aunque la gastronomía vinculada a la caza sea uno de los elementos mejor patrimonializados económicamente en los municipios monteros. Pero cazar, además de un modo de apropiarse materialmente del bosque, y de incidir directamente, también de modo físico, en las relaciones ecosistémicas del territorio forestal, representa un modo de relación cognitiva, mental, con ese mundo. Ambos procesos, el físico-material y el cognitivo-sensorial, no pueden entenderse dicotómicamente, sino que se articulan mediante la acción cinegética, a través del saberhacer de los colectivos de cazadores y rehaleros (y de otros colectivos que tienen a su carga la gestión y custodia de los espacios forestales, como los guardas). Es decir, existe una dimensión pragmática, un saber hacer, que guía los movimientos y estrategias en el monte; pero simultáneamente, existe una dimensión sensorial, emocional, todo lo cual se desarrolla en un marco de normatividad ética, en proceso de discusión permanente. Intentaremos, por tanto, en primera instancia, centrarnos en describir en qué consiste ese modo práctico y cognitivo de inscribirse en el territorio. Aclaremos que lo se describe 
a continuación, a partir de la experiencia etnográfica y de la literatura especializada, hace referencia a un modo de relación ideal. Es decir, no representa la totalidad de las conductas en las monterías, sino que aspira a definir un modo, diríamos, ejemplarizante típico ${ }^{6}$.

Podemos partir de una caracterización genérica de la caza, a partir del concepto presentado por Ortega y Gasset (1999 [1943] y 1960) y de su reformulación por Fernández Trasguerres (1993). A saber: se trata de (a) una ocupación "felicitaria" (ociosa, no relacionada con la subsistencia, sino con el deseo de experimentar sensaciones, por complacencia, gratuita), extremo que queda cubierto mediante los valores socioculturales ya expuestos. (b) Es una actividad no progresiva, pues el adelanto tecnológico arruinaría su sentido, de modo que su efectividad deberá ser resultado de factores como el esfuerzo, el talento e incluso la suerte, lo que supone que siempre entraña algún riesgo, por mínimo que parezca, motivado por la acción del animal. (c) Se debe fundamentar antes en la ritualización de las operaciones de persecución que en la muerte como finalidad última de la actividad. Siguiendo el juego de operaciones de acecho de la caza entre animales, el ser humano ha ritualizado ese tipo relacional y la muerte, de producirse, debe seguir unos principios éticos, también pautados. (d) Como defiende Fernández Trasguerres (1993: 52 y 61), la caza se sustantiva en una relación humano-animal con una dimensión que él denomina numinosa, en el sentido de percepción de cierta sacralidad religiosa, que la separa de una relación basada en una funcionalidad alimenticia ${ }^{7}$. Hablamos de religioso en un doble sentido: con el significado de "religar", mediante creencias trascendentes que llegan a crear una comunidad -en este caso, de relaciones socioecosistémicas, entre hombres, animales y elementos del territorio- y con el de sentido de dotar de legitimidad a la práctica y al discurso (Talego et al, 2015: 3) ${ }^{8}$

6. Podría ser el furtivo quien más se aproxima al modelo bruñido de cazador (y así lo reconocía el Conde de Yebes (Figueroa Alonso, 1943), por ser quien mejor se sitúa en ese espacio intersticial entre el hombre y la naturaleza, que será el aspecto central del modo de pensar y sentir venatorio que vamos a exponer aquí. Sin embargo, queda fuera de la ley y no entramos aquí a considerarlo.

7. Fernández Trasguerres, siguiendo la filosofía de Gustavo Bueno, distingue la "caza radial", sustentada en una relación alimenticia, y que ha estado presente a lo largo de toda la historia de la humanidad, de la "caza angular", basada en una relación de carácter religioso. Desde nuestro punto de vista, ambas dimensiones se han reproducido históricamente, sin que sea posible separarlas. Solo con la irrupción de modelos mecanicistas de la Naturaleza en la tradición filosófica europea occidental, a partir del siglo XVII, empezó a concebirse a los animales, también, como objetos, alienados, lo que afectó a los modos de relacionarse con ellos. Así se abre una visión economicista (naturaleza como recurso, objetivada), que culminará en la idea de que es sustutuible por capital (Naredo, 2003). Estos procesos, como veremos, terminan por afectar a las monterías andaluzas.

8. Esa cualidad religiosa se puede conectar con el modelo organicista con el que los europeos contemplaban las relaciones humano-ambientales en la primera modernidad (Glacken, 1996): búsqueda de la presunta belleza y orden de la naturaleza, interés por la conexión entre sistemas vivos y no vivos, geológicos y celestes, posibilidad de controlar el entorno para salvaguardar, e incluso mejorar, el "diseño inteligente", que se hacía recaer en un dios omnipotente. Era el modelo dominante en las sociedades europeas antes del impulso tecnológico y del desarrollo de modelos mecanicistas sobre todo a partir del siglo XVII. 
En una obra que se ha convertido en biblia profana para los conservacionistas, Walden, la vida en los bosques (1854), H.D. Thoreau aporta una serie de apuntes acerca de las percepciones, los sentimientos y emociones en relación con el bosque, que nos ayudan a entender la relación cognitiva que se desarrolla en la caza, idealmente entendida. Lo más gratificante para Thoreau es saber leer la naturaleza a través de una experiencia directa en ella (mejor que con ella) -independientemente de que, como en el bosque andaluz, su grado de antropización sea elevado-. "A veces me agrada plantarme firmemente en la vida y pasar el día como los animales" (Thoreau, 2005: 246), explica el escritor estadounidense que siente una suerte de relación de intimidad (figura 6). Además, es el ansia de libertad, entendible como desacoplamiento del sistema de normas de la vida social ordinaria, el que empuja al cazador al bosque, según Thoreau. Esto es, saberse y sentirse formando parte de los procesos ecológicos que unen a los animales con las plantas y el resto de elementos del bosque, anticipando así la posición de Ortega y Gasset.

"Cuando el cazador se halla en la espesura del monte (...) se siente en relación con innumerables seres que se ocupan de él: son los animales silvestres, cuya existencia entera es una perpetua alerta ante el cazador, presente o posible. Sabe que cada gesto suyo, que el menor barullo por él producido al moverse o andar, que el olor mismo de su corporeidad humana va a influir en la conducta de los otros seres (...). Esta intimidad, este trato vivacísimo con el animal, esta compañía múltiple, arisca, dramática con los bichos del campo es la delicia básica de la caza. Porque no se trata sólo de la pieza que hemos visto, que perseguimos y que diestramente se esquiva de nosotros, sino de todos los demás que no vemos pero que presentimos que nos han descubierto, que nos espían desde el fondo de sus escondrijos” (Ortega y Gasset, 1960: 455-456)

Figura 6. Postor a la espera del lance, sobre la coscojera, finca de Castiblanco de los Arroyos (Sevilla)

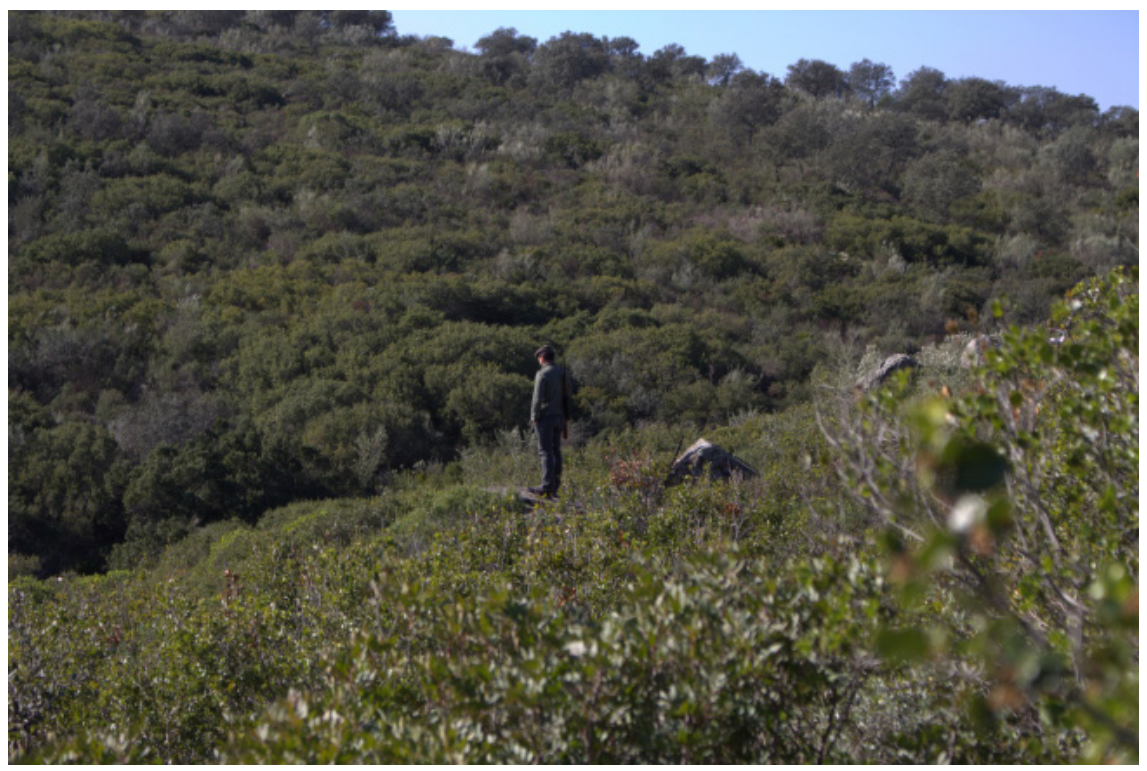

Autor: David Florido 
Para Ortega, no se trata solo de un viaje, si bien transitorio, hacia la naturaleza, sino también hacia la historia, pues le permite imaginarse, siquiera sea temporalmente, como aquel hombre que hacía de la caza su principal actividad, su medio de vida, logrando así, de modo inmediato, la recuperación interna de nuestra condición de ser "natural" (Sánchez Garrido, 2005). De repente, el perrero, el guarda, el montero -siempre y cuando conozcan el territorio y sepan leerlo-, logran religarse (raíz etimológica de religión) a la naturaleza, suspender el tiempo histórico, el del hombre, y entrar en un territorio en el que las voces del bosque afloran, pues "a la naturaleza no le preocupa mostrarse a ellos" -explica Thoreau-, de ahí que "tal vez el cazador sea el mejor amigo de los animales de caza" (2005: 248). Así, el hombre con experiencia en el monte puede conocer práctica e instintivamente esa gramática ecológica que suele ser desconocida para quien no lo conoce $^{9}$. Por ello, el territorio en que la montería tiene lugar, la mancha (trasunto de espacio no limpio, salvaje, menos domesticado), deja de ser un escenario -como sería para un paisajista o un turista- para convertirse en una red de conexiones vivas entre animales, plantas, aromas, vientos y demás elementos atmosféricos... ${ }^{10}$

Este tipo de experiencia se caracteriza por su condición de proceso, en el que la intuición, los sentidos, el conocimiento incorporado, enactado (el pensamiento corporeizado de Varela et al., 1992) juegan un papel relevante, junto con la relación activa -basada en un saber hacer- con el entorno (Ingold, 1992). Nuestra hipótesis es que la continuidad en el tiempo es clave para que esa relación se constituya en un poso cultural, una tradición, de ahí que sea necesaria una interacción permanente en el tiempo, como queda garantizado en las monterías sociales o en el trabajo recurrente de los perreros. Aristóteles, en la Ética a Nicómaco (Libro VI), destaca distintos tipos de conocimiento, que podríamos traducir como vertientes diferenciadas en las relaciones cognitivas del hombre con el mundo:

9. A este respecto, puede resaltarse la siguiente paradoja: el inicio del significativo crecimiento de licencias de caza en España (un indicador de la extensión de las actividades cinegéticas en nuestro país) coincide con el período del desarrollismo de los años sesenta del siglo XX (López Ontiveros, 1986:72). Es decir, que existe una correlación entre el desarrollo de modos de vida que inciden en la des-imbricación entre poblaciones locales y el ámbito rural y el auge de la actividad cinegética. Además del factor cultural que queremos subrayar aquí, habría que considerar el aumento general del nivel de consumo de clases trabajadoras y medias y el incremento de la motorización. Fenómenos sociológicos como la "rural recreation", de la que participan tanto cazadores que proceden de medios urbanos como turistas vienen a apuntar la correlación señalada entre desarrollismo-industrialismo y crecimiento de la actividad cinegética. Un proceso complementario que afecta a Andalucía es el mantenimiento de la actividad cinegética por parte de trabajadores rurales emigrantes, retornados o no (López Ontiveros, 1986: 79).

10. Dicho poéticamente, pero con el mismo sentido: "Tiene el aire, cuando se caza, otro sabor más exquisito al resbalar sobre la piel o visitando el pulmón; la roca adquiere más expresiva fisonomía y el vegetal se carga de significaciones. Pero todo esto se debe a que el cazador, mientras avanza o acurrucado espera, se siente unido por debajo de tierra con el animal que persigue, hállese éste a la vista u oculto o ausente" (Ortega y Gasset, 1999:100) 
la epistémica, de racionalización (sofía); la dimensión técnica (techné), en el sentido de saber hacer; y una tercera frecuentemente olvidada en la Modernidad Occidental: la vertiente de prudencia (la phronesis), que hace referencia al "saber hacer", no en el sentido técnico sino en el de conducirse rectamente, a partir de principios éticos, según valores que se han ido constituyendo en tradición, de ahí que la caza "implique toda una moral" (Ortega y Gasset, 1999: 25).

Desde esta perspectiva podemos considerar las disposiciones que orientan no solo cómo dar muerte en el sentido técnico, sino cómo hacerlo éticamente. Aquí la violencia de la muerte es resultado de un proceso ritualizado mediante una secuencia de actos previos que conducen al fin del animal, como queda expresado en el aforismo clásico "venare non est occidere"11. Ya antes de la partida de caza, en el "pisteo" o "concierto de la mancha", desde el momento en que se inicia la batida de los perreros (figuras 7 y 8), las maniobras de acecho, no "cargar el viento" (evitar ser percibido por nuestro olor en función de la dirección del viento), mimetizarse con el paisaje, conocer las querencias de los animales, etc., son actos que implican concederle al animal inteligencia y voluntad, para presuponer que el animal sabe de su presencia e intenta eludirla -darle su "juego", al decir de Ortega y Gasset (1999:42 y 43)-. Se trata de imaginarse una relación, eso sí jerárquica, que requiere del respeto de un conjunto de normas. Por tanto, para la percepción del "auténtico" cazador, la muerte del animal no es una discontinuidad que altere el curso de relaciones ecosistémicas (cuido el monte, pero mato), sino que se trata de una relación de continuidad, pues así se reproducen los principios naturales (cuido el monte $y$ mato). Por ello, entre los cazadores es recurrente la distinción entre cazadores y "tiradores", "matarifes", "escopeteros", "carniceros" o "intrusos" (Sánchez Garrido, 2006: 10), evidenciando un marco normativo en el que vale renunciar a toda la potencialidad de la superioridad técnica (lo que no quiere decir que esa superioridad quede anulada, ni mucho menos). Es decir, lo esencial en esta relación cognitiva no es la muerte, una muerte técnicamente efectiva, sino experimentar la naturaleza desde dentro, convertirse en un predador y formar parte del ciclo de la vida y la muerte, con ese sentido religioso anunciado. Y de ahí la pertinencia de riesgo, de la incertidumbre, del azar y del fracaso (todos atributos del lance) para que se pueda hablar propiamente de caza en un sentido antropológico más profundo. Ingold (1994) subraya, refiriéndose a sociedades de cazadores-recolectores, la diferencia entre el modo de interacción entre cazadores y pastores, por un lado, y animales por otro. Los cazadores basan su interacción en una relación de confianza mutua, que busca respetar cierta autonomía del animal. El ideal cultural del cazador, a diferencia del del pastor, elude tratarlo como mero objeto de dominio. Lo que queremos subrayar es la posibilidad de que en las monterías sociales se

11. Cazar no es matar. La interpretación de Ortega y Gasset puede ser aclaratoria del sentido profundo de este adagio: "no se caza para matar", sino, que, por el contrario, la muerte es el resultado de haber cazado. 
mantenga este modelo cognitivo, por mucho que su actividad de caza no sea equiparable en otros muchos aspectos a la de sociedades de cazadores-recolectores.

Figuras 7 y 8. Suelta de perros y batida de la rehala con el perrero, Castiblanco de los Arroyos (Sevilla)


Autor: David Florido 
El engaño es la principal de las vías de mediación en la comunicación entre el animal y el cazador en los distintos tipos de caza, siguiendo distintos esquemas: mímesis (vestimenta, pantallas, trampas, aguardos, etc.); alimentación; engaño mediante sonidos animales artificiales -sean humanos o de aparatos-; etológico o sorpresivo (buscando el engaño en los movimientos, en sus lugares de querencia, de paso...); engaño con la ayuda de otros animales (ya sean vivos o muertos) o cinegético (a través de los perros de caza, los que a su vez son entrenados y educados a través del engaño) (Montero Cruzada, 2017). En todo caso, se requiere jugar al engaño con un sentido ético, respetando la condición actante del animal, es decir, de agente que también piensa, siente, tiene voluntad de escapar y podría hacerlo.

La caza permite la reproducción social de lo que el historiador Carlo Ginzburg denominó paradigma indicial ${ }^{12}$ para referirse a estos saberes, resaltando su capacidad para "remontarse desde datos experimentales aparentemente secundarios a una realidad compleja, no experimentada de forma directa" (Ginzburg, 1999: 144). El acto nuclear del acto venatorio es conquistar la ausencia del animal, pues está en su naturaleza ocultarse, siendo ésta su principal arma para vivir. Ante esta realidad, el cazador debe representarse unas relaciones ecológicas que solo conoce fragmentariamente, a través de indicios, y gracias a facultades basadas tanto o más en la intuición y los sentidos (en todo caso, se aprovecha del instinto del perro para lograr su fin) que en la razón. Y esa representación es la que genera un relato sobre lo que ocurre (Hornborg, 2001), incluyendo las dimensiones epistémica, técnica y fronética, aludidas: qué hacer, cómo y por qué hacerlo. Aquí el ecosistema no se define desde fuera (no es una lectura del mundo, científica), sino que se percibe, se siente, se incorpora y se define desde dentro (es una lectura en el mundo), un saber hacer vernáculo, experimental y práctico. No nos sirve para conocer mejor la naturaleza, pero sí para entender más apropiadamente otros modos de interpretarla.

El saber hacer no solo se materializa en las acciones de preparación y ejecución de la caza, sino que se desarrolla en un ámbito poscinegético, desbordando la función estricta de la caza y poniendo de manifiesto esa dimensión de ritualidad ya aludida en la primera parte, al hablar de la noviez. El cazador incorpora la continuidad hombre-naturaleza, al ser embadurnado con la sangre y vísceras de su primera res muerta. No es solo un acto de desagravio por la muerte en una lógica de reciprocidad, sino que la interpenetración hombre-animal es corporeizada a través de la muerte. Desde este mismo punto de vista podemos interpretar la acción ritualizada de "sacar el buche", que hemos podido

12. Partimos de la noción que define Descola (2005 y 2011), como formas cognitivas de organizar los atributos de lo existente, que las distintas sociedades elaboran para interpretar a los seres (humanos y no humanos, animados e inanimados) y a las relaciones entre todos ellos. Para Descola, toda la diversidad posible de cosmologías humanas se puede reducir a cuatro tipos ideales: animista, totémica (estas propias de sociedades de cazadores-recolectores y cultivadores-horticultores primitivos), analogismo (dominante en sociedades jerárquicas premodernas) y naturalismo (el modelo dominante en las sociedades occidentales a partir del siglo XVIII). Esta última cosmología se diferencia de las anteriores por crear una discontinuidad entre naturaleza (objeto, pasiva) y cultura (sujeto, activa). 
constatar en las monterías sociales: un conocimiento enactado, una concepción de la relación hombre-animal corporeizada que se caracteriza por su continuidad.

Si hablamos con un rehalero, veremos también cómo su lenguaje deja aflorar una concepción de las relaciones humano-animales basadas en una concepción orgánica y de traducibilidad hombre-animal. "El perrero no puede mentir a los perros, él es el jefe de la manada"; mientras que, en sentido contrario, del ámbito de la animalidad hacia el orden humano: "el perro debe ser inteligente y tener cabeza, además de olfato que es su instinto", o "hay perros que parecen que hablan". La "dicha" (ladrido del perro en la persecución de la res) constituye un lenguaje que es decodificado por los perreros en las batidas de caza, como resultado del proceso de adiestramiento y acomodamiento mutuo entre hombre y animal, cultura y naturaleza. Es decir, se trata de nuevo de un proceso híbrido, en tránsito, entre estas dos categorías. Como subraya el rehalero Alfonso Aguado (2017), la relación que sostiene el adiestramiento de las rehalas es un vínculo que se despliega en utilidad, pertenencia y afectividad. El animal amaestrado es un estadio entre lo salvaje y lo cultivado, una criatura híbrida, que viene a redefinir, otra vez, que los haceres y saberes que constituyen la tradición cinegética en las monterías vienen a situarse más acá de cosmovisión moderna occidental, al trascender con soltura los férreos límites que aquélla establece entre cultura/naturaleza.

\section{RELACIONES HUMANO-AMBIENTALES EN LAS MONTERÍAS ANDALUZAS. DIVERSIDAD Y CONFLICTO.}

Usando distintos conceptos acerca de modelos de relaciones humanos-ambientales de la teoría antropológica (Descola, 2005, Escobar, 1999 o Pálsson, 1996), queremos plantear si en los debates que han convertido la caza en objeto de disputa política en los últimos años, se están poniendo en juego distintas "ontologías"13, es decir, esquemas de percepción de la naturaleza que permiten pensar, clasificar y relacionarse, "sistemas de propiedades de lo existente que sirven de punto de anclaje de las formas cosmológicas, de los modelos de lazo social y de las teorías de la alteridad" (Descola, 2011: 87). Para plantear el debate, partimos del concepto "régimen de naturaleza" de Arturo Escobar (1999), para referirnos a cada uno de los modelos de hacer-pensar las relaciones humanoambientales, desde distintas agencias, como constituyentes del territorio, del paisaje, en un proceso permanente. Esta aproximación nos permite entender el carácter construido de la naturaleza, esto es, cómo, en cada caso específico, mediante prácticas y discursos, los

13. El paradigma indicial o adivinatorio ha sido desarrollado históricamente por diversos colectivos y en esferas de actividad ciertamente diversas: médicos, historiadores, políticos, alfareros, carpinteros, marinos, cazadores, pescadores... (Ginzburg, 1999: 147). En el caso de la cacería de piezas mayores, es la práctica del "rececho" -o persecución selectiva- la que mejor desarrolla esta dinámica cognitiva. 
colectivos humanos (agencias diversas) dan forma a una "socionaturaleza" ("culturaleza", si se permite el neologismo) impregnada de procesos económicos, políticos, ideológicos. Así, la naturaleza deja de ser un espacio objetivo, externo, autocontenido, más allá y más acá de la acción antrópica, y se convierte en una pluralidad de paisajes cargados de historia y cultura humanas (Bender, 1993). Ocurre, en relación a la caza mayor, que en un mismo período de tiempo y en relación a un territorio específico, conviven conflictivamente distintos "regímenes de naturaleza", que trasladan inmediatamente el debate a la arena política. Así, lo que está en juego en los conflictos que se han ido sucediendo en los últimos años sobre la caza, no son en modo alguno conflictos por subsistencia, sino por distintos conceptos de patrimonialización de la naturaleza: disputas por definirla y por actuar sobre ella (Folchi, 2001).

\subsection{El modelo de las monterías sociales}

Lo que la etnografía nos induce a pensar es que a través de las monterías sociales, los grupos de cazadores y colectivos relacionados experimentan relaciones, tanto sociales como con la naturaleza (conformando así un paisaje vivido en el sentido anunciado), que generan un particular tipo de vinculación con el territorio y entre los agentes con los que interactúan. Esta vinculación produce una identidad social que se traduce, como analizamos en el apartado posterior, en una posición política. Se trata de un modo de pensar y actuar en la naturaleza que podríamos definir por negación: la naturaleza no es una esfera separada, sino que el montero constituye su experiencia e identidad en el territorio; es decir, que el cazador idealmente trazado -encarnado en las monterías sociales- no reproduce el "naturalismo" como modelo dominante en las sociedades occidentales desde la Modernidad, caracterizado por la alteridad y discontinuidad sociedad-naturaleza (Descola, 2005, Escobar, 1999, Soper, 1996). Más bien, se encuentra cómodo en el modelo de continuidad orgánica, mediante esa experiencia de doble dirección: de un lado, presupone a los animales cualidades activas ligadas a su instinto, a sus emociones, a su voluntad, traducibles en términos humanos; recíprocamente, los cazadores se piensan -y sienten- a sí mismos como predadores, injertándose en la gramática de las relaciones ecológicas mediante el rito y autopercibiéndose como un intérprete que aprende a leer el libro de la Naturaleza. La colaboración del perro en este juego de la naturaleza es primordial, reforzando y ampliando la red de interconexiones experimentadas.

"Ahí está el perro, que era desde siempre y por propia inspiración cazador entusiasta. Merced a ello el hombre integra en su cazar el cazar del perro, y lleva así la cacería a su más alta complicación, a su forma más perfecta. Viene a ser lo que en la música el descubrimiento de la polífonía" (Ortega, 1999:62). 
Por tanto, partimos del supuesto de que la caza en las monterías sociales -más allá de sus funciones económicas y sociales- está anclada en significados más profundos que tienen que ver con esa percepción transmitida como tradición que logra mantener una ligazón física, emocional y ética entre las sociedades locales y sus entornos inmediatos, esos lugares vividos (Leff, 2014). Se trata de una relación basada en un conocimiento "enactado", materializado a través de sus sentidos, su cuerpo, incorporando la dimensión emocional. Se trata de un cazador que pertenece a la sociedad local, que se incorpora a una relación histórica de apropiación con un territorio que conoce. Este cazador representa el régimen de naturaleza que se caracteriza por una hibridación cultura-naturaleza. En cuanto a sus marcos de gestión territorial, estas sociedades no tienen ningún interés crematístico: aprovechan usufructuariamente un territorio (el coto) con el que tienen una relación de apropiación, de patrimonialización, de larga data, como ha sido descrito, y la sociedad de cazadores se preocupa por mantener las condiciones adecuadas para garantizar una población cinegética, sin llegar, ni mucho menos, al grado de control intensivo del modelo de las monterías comerciales o de invitación. Económicamente, la asociación exige a sus socios una cuota anual para cubrir los gastos de explotación del coto, sin otra aspiración. Este "régimen de naturaleza" no ha cristalizado, aún, en ningún discurso público relevante; hemos de entenderlo con una experiencia cultural enactada en las prácticas cinegéticas en las monterías sociales; por ello, apenas se tiene en cuenta en el debate social sobre las actividades cinegéticas, cuando, como se ha visto, se despliega en el marco de una normatividad ética sobre cómo deben hacerse las cosas en la mancha, antes, durante y después de la caza.

\subsection{Regímenes de naturaleza en conflicto: ecologistas versus cazadores.}

Las monterías se sitúan en contextos territoriales: las manchas forman parte de un territorio de bosque, sometido a distintos regímenes jurídicos y económicos con dinámicas ecológicas que son insoslayables. Es en este marco en el que se está planteando el conflicto entre organizaciones ecologistas y entidades cinegéticas, entre conservacionistas y cazadores (Sánchez Garrido, 2009b) ${ }^{14}$. En primer lugar, podemos considerar el régimen

14. Como se afirma en este trabajo, frente a un movimiento ecologista "verdirrojo" (por su izquierdismo ideológico), bien articulado y organizado en la arena política, no existe un movimiento similar entre los cazadores, destacables por su heterogeneidad social, formativa, económica..., por mucho que también exista un importante movimiento asociativo, al que se le atribuye capacidad de influir en su ámbito (Ecologistas en Acción, 2017). No entraremos a considerar la posición de grupos animalistas, distinta en sus planteamientos y objetivos a la de grupos ecologistas y radicalmente enfrentada a la de los cazadores 
defendido por los grupos ecologistas (Ecologistas en Acción, 2017) ${ }^{15}$. Su planteamiento se orienta a un polo que entiende la naturaleza como un "dominio independiente de valor intrínseco, verdad o autenticidad" (Soper, 1996: 22), una verdad que podríamos considerar por un sentido numinoso (Talego et. al, 2015 y 2016). Este planteamiento, entendemos, está construido, siquiera de modo implícito, sobre el "naturalismo" que distingue Naturaleza de cultura (Descola, 2011), sobre una serie de dualidades: naturalartificial, puro-impuro, ecosistema-mercado, equilibrio-desequilibrio, biodiversidadbiohomogeneidad, correspondiendo a la naturaleza siempre el primer término del par ${ }^{16}$. Complementariamente, se oponen patrimonio (natural) y recurso (económico), al modo expuesto en Talego et al. (2016: 476 y ss.). Esta construcción discursiva tiene un trasunto político, que enfrenta la ecología (como conocimiento verdadero y que representa el mundo) a la economía [teoría de economía de mercado] (como ideología travestida de ciencia con consecuencias negativas, tanto sociales como ambientales). Del mismo modo, enfrenta el principio comunalidad (el bosque como un patrimonio común y que como tal debe ser regulado) al de individualidad (encarnada por el empresario a la búsqueda del interés económico y sus discursos de justificación: creación de riqueza y de 'empleo'). El trasunto del conflicto, por tanto, es la oposición de la naturaleza entendida como bien patrimonial e inalienable, con valor en sí misma, frente a la finca como bien mercantil alienable, con un valor venal derivado de transacciones comerciales (Talego et. al. 2015: 27), por lo que sus dimensiones desbordan con mucho una querella sobre "el bosque", para penetrar en posicionamientos ideológicos más profundos.

$\mathrm{Si}$, por el contrario, atendemos al régimen de naturaleza defendido desde la posición de organizaciones cazadoras, el mapa es aún más heterogéneo, pues diversos son los modos de gestión de los espacios forestales y de organización de la actividad venatoria. Ya hemos

15. No podemos atender a la diversidad de posiciones que pueda haber en el ámbito del ecologismo organizado, ni en el ámbito de partidos políticos que incorporan entre sus idearios concepciones de la naturaleza próximas a aquél, sino que analizamos sucintamente el documento elaborado por Ecologistas en Acción, por la relevancia pública de esta entidad y su representatividad en Andalucía y el resto del territorio nacional. Sin embargo, hemos de reconocer que, dentro del ecologismo, existe diversidad, que se refleja en las diferentes sensibilidades que existen en relación a la caza, entre posiciones abolicionistas sin matices y propuestas que incorporan la caza entre las actividades antrópicas que ayudan a la regulación y gestión de los espacios forestales, siempre que sea resultado de un proceso político participado por distintas agencias y basado en criterios de racionalidad ecosistémica (Sánchez Garrido, 2009b).

16. Ver en Talego, Coca y del Río (2016) una clasificación de animales y plantas de los campesinos de la sierra de Huelva en relación con la ecología política del buitre Negro en la Sierra de Picos de Aroche. No podemos trasladar a los cazadores tal y como han sido definidos, la consideración de estos autores de que la percepción campesina occidental "desacraliza" la naturaleza, a la que solo puede entender como recurso, como objeto alienado, material y susceptible de aprovechamiento utilitario. 
tratado el caso de las monterías sociales, con escaso o nula proyección en la arena política. Debemos considerar, por tanto, el caso de las grandes fincas organizadas con criterios de rentabilidad económica, pues constituyen el principal objeto de polémica. Aquí nos topamos con el marco de economía capitalista intensiva infiltrada en los espacios forestales -un proceso social intensificado en las últimas décadas-. La naturaleza se entiende como un solar, estéril si las actividades allí desarrolladas no se convierten en generadoras de riqueza, ya sea mercantilización de servicios (cacerías de pago), ya mediante servicios ecosistémicos para favorecer las monterías (gestión forestal para beneficiar la población cinegética). Esta gestión se dirige a garantizar una población de reses cinegéticas, cuya función económica es la rentabilidad del espacio forestal para su propietario y para el empresario que organiza la actividad. Se desplazan usos previos, como el ganadero o la recolección, y se interviene en la finca con distintas medidas: algunas están presentes en otras modalidades de gestión de monterías (aguaderos, comederos, piedras de sal o descastes selectivos), pero otras se viene incorporando vinculadas a este modelo de gestión: vallados y cercones, descaste de ejemplares con “defectos”, ingreso de ejemplares de especies autóctonas y alóctonas para garantizar un buen resultado en el cobro de reses, ataque a especies consideradas "alimañas" que interferirían en la reproducción de los animales salvajes a capturar... Es la "caza de cosecha" de Hell (2001) llevada a su extremo por la vía de una racionalidad netamente capitalista. Como hemos apreciado en el trabajo de campo, otros elementos organizativos de la caza acompañan a este modelo: un alto grado de formalización en las relaciones de trabajo para garantizar el máximo aprovechamiento de todos los elementos del sistema (descaste de reses defectuosas, desmogues -cuernas desprendidas-, eviscerado y despiece de carne mecanizado...).

Como reconoce Fernández Trasguerres, cuando la práctica venatoria quiere disfrutar de las ventajas técnicas que le procura su nivel técnico o su modelo organizativo, "la caza dejaría de ser caza, trocándose en simple matanza" (1993: 59). En la ética arquetípica de la caza, se consideraría esta intervención como un modo de garantizar la muerte de los "bichos", plenamente objetificados, previo pago, a pesar del mantenimiento de determinada ritualidad, pues la relación crematística se acaba convirtiendo en el fin último de la actividad para quien la organiza. Para quien la disfruta (el montero), sin embargo, se trata de una economía ciertamente peculiar, mediante la cual el cazador imputa dinero en un circuito empresarial para obtener una recompensa simbólica, el trofeo de caza ${ }^{17}$. Estaríamos, por tanto, ante otro modelo de relación humano-ambiental,

17. Necesitaríamos una teoría del valor, a lo Appadurai (1986) para comprender la lógica económica del "pagar para matar". Es decir: son los intercambios, inscritos en relaciones de poder, los que dotan de valor a las cosas, un valor que es fundamentalmente político. Podríamos aplicar al valor de las reses abatidas en las monterías algunos de los atributos que Appadurai aplica a los bienes de lujo, que denomina "signos encarnados": dificultad de adquisición, vinculado a una función de "escasez" socialmente construida; capacidad de emitir mensajes complejos ("virtuosidad semiótica"); requerimiento de un conocimiento especializado para un disfrute apropiado; o una intensa relación con aspectos del cuerpo, la persona o la personalidad. A éstos, el antropólogo indio añade el carácter de bien restringido a élites (por leyes o por sistema de precios), que solo sería aplicable a determinados modelos de monterías, precisamente las más capitalizadas. 
en el que la separación sociedad-naturaleza, la reificación de ésta vía conversión en recurso, es el elemento dominante.

Si queremos trascender la frontera ideológica que atraviesa esta arena política en conflicto, cazadores versus ecologistas, hemos de reconocer que ambas posiciones, superando su heterogeneidad interna, están atravesadas por un valor ideal, normativo, que bascula entre dos polos, si tomamos como referencia a Pálsson (2001): el paternalista y el orientalista ${ }^{18}$. Por un lado, el modelo "paternalista", dominado por el valor de regulación que prescribe la conservación a través de la ciencia ecológica y que entiende la naturaleza como bien político de carácter público que debe resguardarse de determinadas intervenciones como la cinegética intensiva- que favorecen a grupos sociales restringidos. Es el discurso ecologista, sustentado sobre la idea de equilibrio prehumano o parahumano (una utopía anacrónica porque estamos situados en un territorio históricamente humanizado). Por otro lado, el modelo "orientalista”, según el cual la naturaleza debe ser gestionada con criterios de racionalidad económica: se busca garantizar la rentabilidad de los espacios forestales, bajo el supuesto de que la regulación de determinados servicios ecosistémicos -los que garantizan las poblaciones cinegéticas- permitirá reelaborar la naturaleza convertida en recurso, en un medio para un fin externo a ella misma. Es muy significativo que un hecho particular, los atropellos de reses salvajes en las carreteras (que tiene como externalidad negativa los accidentes de tráfico), sea leído de modo diferente por ambas racionalidades: para la economicista-orientalista, la caza garantizaría la disminución de atropellos; para la ecologista-paternalista, es un indicador de la sobrepoblación de especies cinegéticas en determinadas zonas forestales mal gestionadas. Siguiendo a Folchi (2001), nos situamos ante un conflicto con contenido ambiental, pero en el que entran en juego otros factores sociales y políticos, que anudan las posiciones en uno y otro campo, de ahí que la tensión sea difícil de atenuar. No se trata solo de que la caza sea imaginada (inadecuadamente) como una actividad de élite, sino de que el modelo de aprovechamiento cinegético que gana territorio en los últimos años drena rentas hacia una minoría social, los propietarios de las grandes fincas. Como reconoce Sánchez Garrido (2009b), estamos ante dos modelos de construcción de naturaleza atravesados por condicionantes de carácter ideológico que tienen que ver, además de con la propia acción venatoria, con nociones sobre la titularidad de los espacios forestales, el papel del Estado, los movimientos asociativos y su capacidad de influencia política. Se trataría, por tanto, de dos discursos que colisionan en el espacio social, cada uno de los cuales incorpora

18. Mientras que el orientalismo representa el régimen caracterizado por entender la naturaleza como tabula rasa en la que se inscribe la cultura humana para su provecho y dominación, convirtiéndola en un medio para un fin (economía) sin valores éticos que intermedien esa relación; el paternalismo representa la conversión en la naturaleza como objeto-fetiche, sobre el que se pretende inscribir un control mediante un conocimiento técnico adecuado (ecología). Al dominio de la matemática y una reciprocidad negativa en el primer caso, se opone el dominio de distintas ingenierías y una reciprocidad equilibrada en el segundo. 
modos de hacer y pensar las relaciones entre sociedad y naturaleza, pero que, además, traen engarzados planteamientos sobre la propiedad de montes, qué función debe tener la economía o cómo gestionar los bosques. Es precisamente este carácter abigarrado de planteamientos sobre las relaciones sociales -incluyendo las ecosistémicas- el que nos permite proponer su carácter "ontológico", el hecho de que sus cualidades penetren no solo las relaciones con el territorio forestal, sino también afecten a modelos políticos y económicos, a ideologías con una cristalización en el espectro político, a distintos colectivos sociales... Y es ese carácter de disputa entre ontologías el que nos ayudaría a entender la crudeza del debate.

\section{REFLEXIONES FINALES}

Nuestra intención ha sido explicar que la montería que sigue el modelo social ubica al sujeto social en un estado privilegiado, el de reinstaurarse momentáneamente en las relaciones ecológicas, aunque desde una posición dominante, en ese tejido de interacciones que lo trascienden y que le permiten una experiencia del mundo particular, con distintas prácticas socio-culturales con valor patrimonial. Es en este sentido, quizá tibio, en el que podemos hablar de este tipo de hacer-pensar en la naturaleza como una ontología. Se trata de una lógica social más contemporánea de lo que podría esperarse, pues ha sido resultado de un proceso histórico iniciado en Andalucía desde la segunda mitad del siglo XX, aunque sus ecos históricos sean mucho más profundos. Este modelo no tiene ninguna portavocía en el debate social sobre la caza. Cazadores que despliegan un saber-hacer en su actividad cinegética "patrimonializan" (hacen suyos) cotos de caza, independientemente de la titularidad jurídica de esa propiedad. Recogen la herencia de la caza como actividad de los espacios forestales, convirtiéndose en uno de los movimientos asociativos de más presencia en la Andalucía desde los años setenta. No solo articulan relaciones entre municipios serranos y parte de su territorio, sino que, vistos los valores sociales y culturales reseñados, constituyen una actividad configuradora de modelos de sociabilidad y experiencia humana que generan una fuerte identidad social y de vincula ción territorial, y así podemos entenderlo como un "régimen de naturaleza" en el sentido expuesto, por mucho que no se haya instituido en un discurso en la arena política de la caza. Aquí radica su fuerza social, y la resistencia esperable en un debate de ecología política sobre la caza, cuyo epíteto "deportiva” puede esconder las aristas y la profundidad de ese conflicto.

Lo más llamativo de este debate social es que, por encima de sus diferencias, las posiciones de ecologistas y asociaciones de caza están invocando una naturaleza normativa, política, intervenida, con distintos grados de mediación humana, si bien a partir de "regímenes de naturaleza" incompatibles y opuestos. Lo que para unos es gestión cinegética que garantiza las poblaciones de reses en el territorio forestal (cotos gestionados con una 
finalidad rentista), para los otros es una "artificialización de los cotos" (Ecologistas en Acción, 2017: 32). Frente a esta aporía de la gestión cinegética de los montes y campos achacable al modelo intensivista, el discurso ecologista reproduce otra, la del tópico de la condición burguesa, o aristocrática, de la caza, no atendiendo, en absoluto, a la diversidad de situaciones sociales que le sirven de soporte, ni tampoco a la diversidad de modelos o regímenes de naturaleza que podemos constatar en la caza mayor andaluza. A pesar de que entre determinados círculos del movimiento ecologista no se rechaza una gestión de territorios cinegéticos realizada conforme a criterios de racionalidad sustentable (controlar las poblaciones cinegéticas en relación a la densidad arbórea y arbustiva; garantizar la no invasión de especies alóctonas; limitar el contacto entre reses salvajes y estabuladas para limitar la transmisión de enfermedades; garantizar el equilibrio entre machos y hembras, etc.), queda implícita una concepción de naturaleza en equilibrio, un modelo utópico y normativo -esa esfera incontaminada, independiente de los usos sociales, tan cara a la mentalidad "naturalista" moderna occidental-, antes que social e histórico. Puede ser la razón por la que los valores sociales y culturales que hemos querido evidenciar aquí escapan al enfrentamiento entre grupos ecologistas y entidades representativas de la caza.

La caza mayor tiene en el caso andaluz una importante diversidad interna, en términos sociales y económicos. Hay una clasificación de modalidades de explotación-gestión; y no puede concluirse sin más que los espacios cinegéticos existentes se ajustan a una gestión mercantil, por mucho que sea preciso, en todos los cotos, una gestión económica y por mucho que, como ha sido puesto de manifiesto, la importancia económica de la caza, con los cálculos realizados, sea de consideración ${ }^{19}$, aunque cualquier analista reconoce la importancia en el sector de actividades no declaradas y el carácter estimativo de los datos.

Ello no obstante, incluso en los casos tendentes a la gestión capitalista de las fincas donde se realiza la caza mayor, es preciso diferenciar las distintas escalas y relaciones implicadas. Incluso en un marco de gestión capitalista de servicios ecosistémicos, la totalidad de los agentes implicados no tienen por qué compartir el hacer-pensar de la naturaleza-recurso. De hecho, desde el punto de vista utilitario, la acción venatoria desde la perspectiva del

19. Para el caso español puede servir de referencia el trabajo de Garrido Martín (2012), donde se hace una valoración estimativa y global de todos los subsectores de la caza en 3.635.756.996 €, para 2011. Los subsectores incluidos son: flujo económico inducido por capturas, veterinarios en captura de especies de caza mayor, taxidermia, rehalas, armas y cartuchería, armería y complementos, perro como auxiliar del cazador, gastos por tenencia de armas y licencias federativas, licencias de caza y seguros, seguros de los cotos, arrendamiento de cotos, planes de ordenación cinegética, guarderías, medios de comunicación, sector restauración y hostelería, sector transporte, sector energía y gestión del coto. A pesar del detalle sub-sectorial, muchas de estas actividades son pobres en datos. Los datos de empleo sobrepasan los 30.000 (para 2002). Para Andalucía, el cálculo de total de la renta cinegética asciende a 1.076.682.608 € (Campos Palacín et al, 2015). 
montero es de una muy dudosa racionalidad (rentabilidad), y solo se podría describir atendiendo a valores simbólicos no crematísticos, como hemos comentado. Aquí radica otra impotencia del discurso ecologista más crítico.

Proponemos trasladar el énfasis de los ecosistemas a los socio-ecosistemas, teniendo en cuenta su complejidad y los valores socioculturales e históricos de la caza en los municipios serranos andaluces. Ello no supone abandonar un enfoque ecosistémico, sino encastrar las actividades humanas y someter éstas a los procesos de ajustes y reajustes de una ecología cultural holista. Solo comprendiendo la caza como fruto de un proceso histórico de apropiación material y cognitiva del territorio, constituido en lugar, podremos avanzar en el establecimiento de reglas para un debate sobre la gobernanza de la caza, en el que participen, desde sus distintos regímenes de naturaleza, todos los colectivos implicados. Como destaca Blaser (2009) no es posible plantear un debate ni teórico ni político sobre cualquier conflicto ambiental si no es atendiendo a las perspectivas culturales de los grupos humanos involucrados, siendo un aspecto clave sus nociones de naturaleza y las relaciones que mantienen los seres humanos con ella. Esta diversidad es ocultada cuando usamos el rubro 'naturaleza' como una entidad autocontenida y al margen de las prácticas y valores humanos. 


\section{REFERENCIAS BIBLIOGRÁFICAS}

Aguado Puig, Alfonso (2017) "La rehala como vínculo asociativo". Jornada "Caza y Cultura”. Facultad de Geografía e Historia. Universidad de Sevilla. Ponencia no publicada. Álvarez Munárriz, Luis (2007) "Conciencia y conducta medioambiental: los paisajes culturales”. Intersticios. Revista Sociológica de Pensamiento Crítico. 1 (1).

Appadurai, Arjun (1986) "Introducción: Las mercancías y la política del valor". En Arjun Appadurai (ed.), La vida social de las cosas. Perspectiva cultural de las mercancías. México: Grijalbo - Consejo Nacional para la Cultura y las Artes (Conaculta), pp. 17-87. Ariño, Antonio (2002) "La patrimonialización de la cultura y sus paradojas en la sociedad del riesgo”. En García Blanco, JMª. y P. Navarro (eds.) ¿Más allá de la modernidad? Las dimensiones de la información, la comunicación y sus nuevas tecnologías. Madrid: Centro de Investigaciones Sociológicas, pp. 329-350.

Augé, Marc (2001) Los no lugares. Espacios del anonimato. Una antropología de la sobremodernidad. Brcelona: Gedisa Editorial.

Bender, Barbara (ed.) (1993) Landscape: Politics and Perspective. Oxford: Berg.

Berger, Peter. y Luckman, Thomas (2003) La construcción social de la realidad. Buenos Aires: Amorrortu Editores.

Blaser, Mario (2009) “The Threat of the Yrmo: The Political Ontology of a Sustainable Hunting Program”. American Anthropologist, 111(1), pp. 10-20.

Campos Palacín, Pablo y otros (2015) Memorias científicas de RECAMAN. vol. 3 y 4. CSIC - Junta de Andalucía.

Carrera Díaz, Gema (2016) Propuesta metodológica para la documentación y gestión del patrimonio cultural inmaterial como estrategia de desarrollo social y territorial. Tesis Doctoral, Universidad de Sevilla. Director: David Florido, Codirector: Juan Agudo.

Descola, Philipe (2011) "Más allá de la naturaleza y la cultura”. En Leonardo Montenegro Martínez (ed.) Cultura y Naturaleza. Bogotá: Jardín Botánico de Bogotá, JCM, pp.75-97. Descola, Philipe. (2012) [2005] Más allá de la naturaleza y la cultura. Buenos Aires: Amorrortu Ediciones.

Díaz de Rada, Ángel (2010) Cultura, Antropología y otras tonterías. Madrid: Trotta.

Ecologistas en Acción (2017) El impacto de la caza en España. Ecologistas en Acción. Accesible en https://www.ecologistasenaccion.org/IMG/pdf/informe-impacto-caza.pdf, [consultado el 9 de julio de2017].

Escalera Reyes, Javier (2012) "Sociabilidad, relaciones de poder y cultura política en Andalucía”. En Agudo Torrico, J. y Moreno Navarro, I. (coords.) Expresiones culturales andaluzas. Sevilla: Aconcagua Libros, pp. 127-163 
Escobar, Arturo (1999) After Nature. Steps towards an Antiessentialist Political Ecology. Current Anthropology, 40 (1), pp. 1-30.

Fernández Trasguerres, Alfonso (1993) Los dioses olvidados. Caza, toros y filosofía de la religión. Oviedo: Pentalfa.

Figueroa Alonso-Martínez, Eduardo (Conde de Yebes) (1943) Veinte años de caza mayor. Madrid: Editorial Plus Ultra.

García García, José Luis (1998) "De la cultura como patrimonio al patrimonio cultural". Política y Sociedad, 27, pp. 9-20.

Garrido Martín, José L (2012) “La caza. Sector económico. Valoración por subsectores". Foro La responsabilidad de los accidentes de tráfico con fauna silvestre. Federación Nacional de Caza y Fedenca. Disponible en internet:

http://oficinanacionaldecaza.org/descargas/318/ [consultado el 9 de julio de 2017].

Ginzburg, Carlo (1999) Mitos, emblemas, indicios. Barcelona: Gedisa.

Hell, Bertrand (2001) "Cazadores rabiosos. El dominio del salvajismo en el este noreste de Europa”. En Descola, Ph. y Palsson, G. (eds.) Naturaleza y Sociedad. Perspectivas antropológicas. México: Siglo XXI Editores, pp. 237-251.

Hornborg, Alf. (2001) "La ecología como semiótica. Esbozo de un paradigma contextualista para la ecología humana”. En Descola, Ph. y Palsson, G (eds.). Naturaleza y Sociedad. Perspectivas antropológicas. Madrid: Siglo XXI editores, pp. 60-79.

Ingold, Tim. (1992) "Culture and the Perception of the Environment". En: E. Croll y Parkin, D. (eds.). Bush Base: Forest Farm. London: Routledge, pp. Pp. 39-56.

Ingold, Tim. (1994). "From Trust of Domination: An alternative history of human-animal relation." En Manning A. y Serpell J. (eds) Animals and human society: changing perspectives. Londres y Nueva York: Routledge, pp. 61-76.

Jiménez de Madariaga, Celeste. (2005) "Ritos y mitos en torno a la caza". En Roque, A. et al. Los animales: del mito al rito. Salamanca: Centro de Cultura Tradicional Ángel Carril y Diputación de Salamanca.

Kockel, Ulrich (2007) "Reflexive Traditions and Heritage Production". En Koeckel U. \& M. Nic Craith (eds.) Cultural Heritages as Reflexive Traditions. New York: Palgrave McMillan, pp.19-32.

Leff, Enrique (2014) La apuesta por la vida. México, DF: Siglo XXI.

Ley 14/2007, de 26 de noviembre, del Patrimonio Histórico de Andalucía

Ley 10/2015 de 26 de mayo para la Salvaguardia del Patrimonio Cultural Inmaterial.

López Ontiveros, Antonio (1986) “Caza y actividad agraria en España y Andalucía. 
Evolución reciente". Agricultura y Sociedad, 40, pp. 67-97.

Montero Cruzada, Santiago (2017) "El engaño como fundamento semiótico para el encuentro entre cazadores y animales", II Seminario de la Red de Antropología Ambiental 'Etnografías alter-humanas: encuentros en la fase animal'. Universidad Pablo de Olavide. Ponencia no publicada. Comunicación Oral.

Naredo, José Manuel (2003) La economía en evolución: historia y perspectivas de las categorías básicas del pensamiento económico. Madrid: Siglo XXI.

Ortega y Gasset, José (1999) [1943] Prólogo a Veinte años de caza mayor del Conde de Yebes. Cuenca: Ediciones de la Universidad de Castilla-La Mancha.

Ortega y Gasset, José (1960) La caza y los toros. Madrid: Revista de Occidente.

Palenzuela, Pablo (1995) "Las culturas del trabajo: una aproximación antropológica". Sociología del Trabajo, 24, pp. 3-28.

Palenzuela, Pablo (2005) "El patrimonio inmaterial de los poblados de colonización: memoria colectiva y culturas del trabajo", en PH 52. Boletín del Instituto del Patrimonio Histórico, pp. 94-101.

Palenzuela, Pablo y Hernández, Javier (1995) Poner Monachil en el mapa. Estudio antropológico de un proceso de transformación cultural. Granada: Universidad de Granada y Diputación de Granada.

Pálsson, Gisli (2001) "Relaciones humano-ambientales. Orientalismo, paternalismo y comunalismo". En Descola Ph y Pálsson, G. (coords.) Naturaleza y sociedad. Perspectivas antropológicas. México: Siglo XXI, pp. 80-100.

Sánchez Garrido, Roberto (2005) "Percepción y rentabilidad cinegética: la hipótesis del verdadero ecologista”. Periferia, 7, pp. 1-21.

Sánchez Garrido, Roberto (2006) "De caza y cazadores. Las construcciones teóricas sobre la actividad cinegética actual a partir de los discursos de sus actores". Gazeta de Antropología, 22, art. 18, pp. 1-15.

Sánchez Garrido, Roberto (2009a) "Cazadores y ecologistas. Análisis antropológico de posturas encontradas". Revista de la Facultad de Ciencias Sociales y Jurídicas de Elche, I (4), pp. 196-215.

Sánchez Garrido, Roberto (2009b) "La caza desde la antropología social y cultural: una aproximación al estado de la cuestión". Revista de Antropología Experimental. 9, Universidad de Jaén.

Sánchez Garrido, Roberto (2010) Caza, cazadores y medio ambiente: breve etnografía cinegética. San Vicente [del Raspeig] Alicante, Club Universitario. 
Soper, Kate (1996) "Nature/'nature". En Robertson, G. et al. (eds.). FutureNatural. London: Routledge, pp. 22-34.

Talego, Félix, Coca, Agustín y Del Río, Ángel. (2015) Movimiento ecologista e identidad andaluza. PR163/12. Taller 'Movimiento Ecologista e Identidad Andaluza'. Fundación Centro de Estudios Andaluces, Sevilla. Documento no publicado.

Talego, Félix, del Río, Ángel y Coca, Agustín (2016) “¿Patrimonio Natural o recurso productivo? El conflicto ambiental en Sierra Pelada en torno al buitre negro". Revista de Dialectología y Tradiciones Populares, LXXI, (2), pp. 467-486

Thoreau, Henry D [1854] (2005) Walden. Madrid: Cátedra.

UNESCO (2003) Convención Internacional para la salvaguardia del Patrimonio Cultural Inmaterial. París.

Varela, Francisco J, Thompson, Evan y Rosch, Eleanor (1992). El cuerpo presente. Las ciencias cognitivas y la experiencia humana. Barcelona: Gedisa.

Vincent, Odile (1987) “Chasse et rituel” Terrain, 8- Rituels contemporaines. pp. 63-70. 